Article

\title{
Assessing the Static and Dynamic Efficiency of Scientific Research of HEIs China: Three Stage DEA-Malmquist Index Approach
}

\author{
Wuzhao Xue ${ }^{1}$, Hua Li ${ }^{1}$, Rizwan Ali ${ }^{2, *(D)}$, Ramiz ur Rehman ${ }^{2,3}$ and Gonzalo Fernández-Sánchez ${ }^{4}$ \\ 1 School of Economics and Management, Xidian University, Xi'an 710126, China; xuewz@xidian.edu.cn (W.X.); \\ lihua@xidian.edu.cn (H.L.) \\ 2 Lahore Business School, The University of Lahore, Lahore 54100, Pakistan; ramiz_rehman@xpu.edu.cn \\ 3 School of Management, Xi'an Polytechnic University, Xi'an 710048, China \\ 4 Department of Operations \& Data Science, EAE Business School, 28002 Madrid, Spain; \\ gonzalo.fernandez@emtmadrid.es \\ * Correspondence: rizwan.ali@lbs.uol.edu.pk
}

Citation: Xue, W.; Li, H.; Ali, R.; Rehman, R.u.; Fernández-Sánchez, G. Assessing the Static and Dynamic Efficiency of Scientific Research of HEIs China: Three Stage DEA-Malmquist Index Approach. Sustainability 2021, 13, 8207. https:// doi.org/10.3390/su13158207

Academic Editor: Yuri Borgianni

Received: 13 May 2021

Accepted: 19 July 2021

Published: 22 July 2021

Publisher's Note: MDPI stays neutral with regard to jurisdictional claims in published maps and institutional affiliations.

Copyright: (c) 2021 by the authors. Licensee MDPI, Basel, Switzerland. This article is an open access article distributed under the terms and conditions of the Creative Commons Attribution (CC BY) license (https:/ / creativecommons.org/licenses/by/ $4.0 /)$.

\begin{abstract}
Higher education institutions (HEIs) are the key to the economic and social development of a country. However, the recent advancements of higher education institutions' universities in China have become a pivotal factor contributing to their swift growth. Considering the impact of the external environment, applying a three-stage data-envelopment analysis (DEA) and the Malmquist index method, we evaluated the static and dynamic efficiency of input-output data of scientific research produced by universities directly under the Ministry of Education in the period of 2010 to 2017. Results showed that the three stage DEA model is more accurate than the traditional DEA method for measuring the efficiency of scientific research input and universities' output. The overall efficiency of universities' scientific research activities increased at an average annual rate of $3.7 \%$ from 2010 to 2017. Further analysis showed that the optimization of the scale was the primary internal factor able to promote the efficiency of scientific research in universities. Technological progress slightly diminishes the efficiency of scientific research in universities, which should, therefore, take measures to improve pure technical efficiency to enlarge the scale of their scientific research according to the characteristics of scientific research efficiency. Such steps will strengthen internal motivation towards scientific research efficiency in universities.
\end{abstract}

Keywords: efficiency; scientific research; environment; three stage DEA; Malmquist index

\section{Introduction}

Technological advancements increasingly playing a distinguished role in the growth of dominant industrial economics. Therefore, governments consciously shift their attention towards research and innovation policies. Scientific and technological innovation are the power source of national development, and universities are their cradle. In recent years, the Chinese government has increased investment in scientific research funds, guided active co-operation between various fields and universities, and promoted the improvement of scientific research innovation. According to the compiled statistics on the science and technology programs of higher learning institutions, the total amount of scientific research funding in Chinese universities increased from RMB 45.758 billion in 2006 [1], to RMB 177.289 billion in 2017 [2], an increase of $287.45 \%$. However, whether these increased scientific research resources are being properly utilized has become a focus. For instance, universities cultivate scientific and technological innovations, and have obvious advantages in carrying out scientific research work. Considering the importance of universities, they have a responsibility to grow knowledge innovation. Universities' research outcomes are the key factors to increasing economics; therefore, assessing their efficiency is an important aspect. 
In China, in terms of creating an atmosphere for scientific and technological innovation in universities, government support and enterprise participation have shown a continuously growing trend [3]. Generally, the scientific research, innovations, advancements, and technologies developed by higher institutions could enhance socio-economic development, which has become a national strategy in many countries, including China, leading to the application of this strategy [4]. In 2015, China stipulated that scientific research institutions and universities established by the state can independently decide on the transfer, license, or price of the scientific and technological achievements held by them. Compared with developed countries, Chinese universities enhance adequate investment in technology innovation, infrastructure conditions, regional distribution, developed scientific research teams, scientific research management mechanisms, and innovation transformation. These initiatives gradually improve the universities' research output and further contribute to economic development.

In recent decades, China's economic growth has resulted in its inclusion in considerations of global economic superpowers. China is the world's second largest economy and the largest exporter by value. Still, it also invests in academic institutions to promote scientific research output and develops scientific research management teams. Furthermore, China recently unveiled new regulations on 14 May 2021 concerned foreign investment in the education sector, which will be effective from 1 September 2021 onward and eventually will contribute to the education industry in China. Therefore, the motivation of this study is to evaluate the scientific research output of higher education institutions and enhance this discussion pattern in China's context with primary focus on the universities directly monitored by the Ministry of Education. For instance, (1) we used a unique data set of 64 scientific research universities directly monitored under the Ministry of Education and which significantly contribute in the field of scientific research output; (2) selecting the three stage DEA method to filter the environmental and random factors, and analyzed the static efficiency of scientific research of universities. This model uses a similar stochastic frontier method (SFA) to eliminate the influence of environment and random interference terms; and (3) used the Malmquist index to analyze the dynamic effects of universities' scientific research.

The study results reveal that the three stage DEA model is more accurate than the traditional DEA method for measuring the efficiency of scientific research input and universities' output. The overall efficiency of universities' scientific research activities increased over the sampled period at the rate of 3.7\% annually. Additionally, analysis showed that the optimization of the scale was the primary internal factor capable to promote the efficiency of scientific research in universities. Technological progress slightly diminishes the efficiency of scientific research in universities. The study extends the literature by estimating universities' static and dynamic efficiency by applying appropriate assessment methods. The study findings offer reasonable, practical, and policy implications for policymakers and stakeholders in China's higher education sector and, mainly, those institutions (universities) which the Ministry of Education directly monitors.

The rest of the paper will proceed as follows. Section 2 will review the extant literature. Section 3 will discuss the research methodology, including variable selection, data sources, and sample. Section 4 deals with the results and discussions while, Section 5 concludes the study.

\section{Literature Review}

Literature reports universities have experienced historical paradigm shifts and tried to align with the current global practices. Universities are always strict with the teaching standards, along with humanism [5]. Gradually, these practices shifted towards research culture, which is exceptionally beneficial for universities' growth, output, and rankings, and contributes to a global community by creating skillful individuals and teams for society, promoting economic development, and stimulating knowledge advancement. Universities improve their services to individuals and social welfare by combining teaching, research, 
technology, and consultations. Traditionally, the transition of knowledge development varies in different economics, including China, which is devotedly investing in the education sector to promote knowledge. To promote the efficient commercialization of university knowledge, higher education institutions' scientific research output has increased rapidly. The literature focuses on assessing higher institutions' research output, a method to evaluate the efficiency of higher education institutions, its determinants in developed states such as the US [6], European countries [7], and so on. However, scarce evidence is reported in the literature on emerging economic contexts such as China.

In the literature, we have found ample research and empirical evidence in the developed states perspective based on earlier legislation on science commercialization. For example, [8] conducted a study to measure the efficiency of higher education institutions using the data envelopment analysis technique in England, and concluded that the English higher education sector appears to be high on average. Ref. [9] evaluated publicly financed higher education institutions in Germany using 72 German public universities. The traditional data envelopment analysis and the stochastic frontier analysis applied revealed that the universities located in the east region of Germany perform better, based on the total factor productivity, than the west region universities. At the same time, the mean efficiency score was better for west region universities. Ref. [10] reported that Italian universities' research activities' outcomes considered the university research staff as input and the output as the standardized field impact of research productivity and realized by the research member. This research stream continues in the developed states with different research techniques and models considering the institutional framework. Ref. [11] examined the efficiency of 259 public higher education institutions from Europe through a two stage DEA analysis. The results revealed significant variability between efficiency scores because the unit size includes economic conditions, faculties, funding sources, and gender composition. This study's critical factor contributing to the debate of higher education institutions is a share of funds from external sources, which improves institution efficiency overall.

Despite the fact that universities' research output has been merely reported in the advance economies, in recent decades this trend shifted towards emerging economies, especially; China has focused on it and continuously reported higher education institutions' research output. For instance, domestic and international research conducted, and the reported empirical evidence of Chinese universities' scientific research output consider different internal and external factors. Such as, [12] revealed unique findings based on those research institutions monitored by the Chinese Academy of Science and concluded that the institutions experienced sufficient improvements in system efficiency through R\&D, and there is much room to improve scientific and technological advancement. Ref. [13] reported the dynamic change of scientific research of Guangzhou Institute of Respiratory Diseases based on the Malmquist index. They concluded that institutions' efficiency is generally high due to the advancement of technology and suggested the optimization of resources as an essential factor and the adoption of new technology.

Ref. [14] conducted a study based on 18 higher education institutions and measured overall efficiency into two divisions. The research development stage and research innovation stage presented that HEIs with social science research are better and proposed to establish an academic sharing system, which eventually pools the experience, knowledge, and capacities of the academic profession within and between regions. Other domestic scholars such as $[15,16]$ evaluated the scientific research efficiency of different types of universities considering various factors. In addition, $[17,18]$ evaluated the scientific research efficiency of Chinese universities in various provinces and regions, and rated them based on their performance. Further, [19-21] conducted a dynamic evaluation analysis on the scientific research efficiency of higher education institutions located in various provinces, and reported that the performance of university research output gradually increased.

The literature has discussed higher education institutions' research performance and reported exciting facts about the research emerging out of universities considering different economies, regions, and factors, and offered new directions for further investigation. For 
example, as one of the leading growing economies globally, China invests in higher education institutions 'universities' significantly and research measures universities' efficiencies. The literature reported this pattern in the Chinese context continuously, which needs to be investigated further in China and offer new findings. For instance, this study examines the scientific research output of Chinese universities using a unique sample of universities, which are directly monitored and reported by the Ministry of Education, China. Therefore, this provides new empirical evidence using a novel set of observations, unique internal and external factors, methodological techniques, three stage data envelopment analysis, and the Malmquist index method to contribute to the literature, and offer new insights for further research and policy developments.

\section{Methodology}

The traditional data envelopment analysis (DEA) model has been utilized in the literature to calculate the relative efficiency of multiple input and output decision-making units (DMUs). At the same time, researchers reported some drawbacks of this model. [22] proposed a three stage DEA model based on the traditional DEA model. The three stage DEA model corrects the deficiencies of the traditional DEA model, eliminates the influence of environmental factors and random errors, and makes the efficiency value more genuinely reflect the actual level. This model uses a similar stochastic frontier method (SFA) to eliminate the influence of the environment and random interference terms. Thus, all decision-making units (DMUs) have the same environment and more accurately obtain the efficiency level of decision units. The method applied in this study consisted of three stages: First, without considering the impact of the environment, the traditional DEA method was used to calculate the DEA efficiency and relaxation variable values of the unfiltered environment based on input or output orientation. Second, a similar stochastic frontier method was used to decompose the input or output variables. The relaxation variables after decomposition included three factors: environment, randomness, and management. Third, the DEA model was used again to evaluate efficiency. Input data after adjustment were the input variables. The original output data were still the output data, thus obtaining an efficiency value of each decision-making unit that excluded environmental and random factors.

In the CCR model there are $n$ DMUs to be evaluated, and each DMU $j(j=1, \ldots, n)$ has $m$ inputs (resources) and $s$ outputs (products), which are denoted with the vectors $x_{j}=\left(x_{1 j}, \ldots, x_{m j}\right)^{\mathrm{T}}$ and $y_{j}=\left(y_{1 j}, \ldots, y_{s j}\right)^{\mathrm{T}}$, respectively. DEA aims to maximize the scalar measure of efficiency $\left(e_{0}\right)$ of the DMU0, the production unit being evaluated, which is defined as the ratio of the weighted sums of the products to the weighted sum of resources using the following fractional programming model (1):

$$
\begin{gathered}
\max _{\mu, \omega}=\frac{\sum_{r=1}^{s} \mu_{r} y_{r 0}}{\sum_{i=1}^{m} \omega_{i} x_{i 0}} \\
\frac{\sum_{r=1}^{s} \mu_{r} y_{r 0}}{\sum_{i=1}^{m} \omega_{i} x_{i 0}}=\leq 1(j=1, \ldots, n) \\
\mu_{r}, \omega_{i} \geq 0(r=1, \ldots, s i=1, \ldots, m)
\end{gathered}
$$

where $\omega_{i}$ and $\mu_{r}$ represent $i$ - th input and $r$ - th output weights for DMU0.

$$
\begin{gathered}
\operatorname{Min} \eta_{0}=\sum_{i=1}^{m} \omega_{i} x_{i 0} \\
\text { s.t. } \\
\sum_{r=1}^{s} \mu_{r} y_{r 0}=1
\end{gathered}
$$




$$
\begin{gathered}
\sum_{r=1}^{s} \mu_{r} y_{r j}-\sum_{i=1}^{m} \omega_{i} x_{i 0} \leq 0(j=1, \ldots, n) \\
\mu_{r}, \omega_{i} \geq 0(r=1, \ldots, s i=1, \ldots, m)
\end{gathered}
$$

where $\omega_{i}$ and $\mu_{r}$ represent the most favorable set of weights for DMU0 in maximizing the previous ratio, which is given by $e_{0}=\frac{1}{\eta_{0}}$. Despite the objective function, (2) is to maximize the weighted sum of inputs; this is equivalent to maximize the efficiency of expression (1). It is assumed that the data is non-negative and that each DMU has at least one positive input and output value. The previous model can be expressed in matrix notation as follows (3):

$$
\begin{gathered}
\operatorname{Min} \eta_{0}=\omega^{\mathrm{T}} x_{0} \\
\text { s.t. } \\
\mu^{\mathrm{T}} y_{0}=1 \\
\mu^{\mathrm{T}} \mathrm{Y}-\omega^{\mathrm{T}} X \leq 0 \\
\mu \geq 0, \omega \geq 0
\end{gathered}
$$

Ref. [23] suggest a model to determine technical and scale efficiency. This BCC model adds a new variable $v_{0}$ to allow variables to return to scale (4).

$$
\begin{gathered}
\operatorname{Min} Z=\omega^{\mathrm{T}} x_{0}-v_{0} \\
\text { s.t. } \\
\mu^{\mathrm{T}} y_{0}=1 \\
\mu^{\mathrm{T}} \mathrm{Y}-\omega^{\mathrm{T}} \mathrm{X}+v_{0} \leq 0 \\
\mu \geq 0, \omega \geq 0, v_{0}
\end{gathered}
$$

The DEA method was used to evaluate the static efficiency of decision-making units in the same period, while the Malmquist total factor productivity index was used to calculate the panel data of decision-making units in different periods, and then obtain the dynamic trend of decision-making-unit efficiency. The dynamic Malmquist total factor productivity (TFP) index was proposed by [24] on the basis of the DEA method, for the purpose of investigating the dynamic characteristics of economic efficiency. [25] proposed the Malmquist index; later, [26] modified the Malmquist index by decomposing on the basis of variable-scale return assumptions. The principle was to select a year's technical efficiency as a reference (this paper used adjacent references) with which to investigate changes of TFP in the reporting period compared with the previous year. Its most prominent characteristic is that it can be effectively used to measure efficiency changes at different time points, and it can be applied to the dynamic analysis of multiple regions in different periods. At the same time, the total factor productivity can be divided into technical-efficiency and technological-progress changes, which is conducive to assessing the real reasons behind a shift in scientific research productivity. The basic principle is as follows: let $X_{t}$ and $Y_{t}$ represent the input and output vectors of the $\mathrm{T}$ period, respectively. DT presents the distance function, with T-period technology as the reference.

For each time period $t, t=1, \ldots, T$, the production technology $S^{t}$ models the transformation of input $x^{t} \varepsilon R_{+}^{M}$ into outputs $y^{t} \varepsilon R_{+}^{M}$ where $S^{t}=\left\{\left(x^{t}, y^{t}\right): x^{t}\right.$ can produce $\left.y^{t}\right\}$. The technology is assumed to satisfy properties sufficiently strong to allow the definition of a meaningful output distance function.

The output distance function is defined at $t$ as

$$
D_{0}^{t}\left(x^{t}, y^{t}\right)=\inf \left\{\theta:\left(x^{t}, y^{t} / \theta\right) \varepsilon S^{t}\right\}
$$


This function is a complete characterization of the technology. It satisfies certain properties; in particular, it is homogenous of degree +1 in outputs. We note that $\left(x^{t}, y^{t}\right) \varepsilon S^{t}$ if and only if $D_{0}^{t}\left(x^{t}, y^{t}\right) \leq 1$.

In order to define a Malmquist output-based productivity index in the spirit of Caves et al. (1982a), we also need to relate an input-output vector $\left(x^{t}, y^{t}\right)$ at time period $t$ to the technology $S^{t+1}$ at the following period. Thus we define

$$
D_{0}^{t+1}\left(x^{t}, y^{t}\right)=\inf \left\{\theta:\left(x^{t}, y^{t} / \theta\right) \varepsilon S^{t+1}\right\}
$$

One may define $D_{0}^{t}\left(x^{t+1}, y^{t+1}\right)$ in a similar fashion; in this case, an observed inputoutput vector produced in period $t+1$ is compared to technology in the previous period $t$. The value of the mixed-period distance functions will be less than or equal to unity if and only if the observations being assessed are "feasible," i.e., are members of technology in the other period. Clearly, if technical progress occurs over time, $\left(x^{t+1}, y^{t+1}\right) \notin S^{t}$ and $D_{0}^{t}\left(x^{t+1}, y^{t+1}\right)>1$. This may cause computational problems, an issue which is discussed below.

We now define our Malmquist output based productivity index as

$$
M_{0}^{t+1}\left(x^{t+1}, y^{t+1}, x^{t}, y^{t}\right)=\left[\frac{D_{0}^{t}\left(x^{t+1}, y^{t+1}\right)}{D_{0}^{t}\left(x^{t}, y^{t}\right)} \frac{D_{0}^{t+1}\left(x^{t+1}, y^{t+1}\right)}{D_{0}^{t+1}\left(x^{t}, y^{t}\right)}\right]^{1 / 2}
$$

The index in above equation differs slightly from the formulation of the Malmquist productivity index. The index in above equation is the geometric mean of two of their Malmquist productivity indices. In addition, in their work, Caves, Christensen and Diewert assume that $D_{0}^{t}\left(x^{t}, y^{t}\right)$ and $D_{0}^{t+1}\left(x^{t+1}, y^{t+1}\right)$ equal 1, i.e., in Farrell's terminology, there is no allowance for technical inefficiency. Here, we relax that assumption, and allow for inefficient observations.

An equivalent way of stating the Malmquist output-based productivity index is

$$
M_{0}^{t+1}\left(x^{t+1}, y^{t+1}, x^{t}, y^{t}\right)=\frac{D_{0}^{t+1}\left(x^{t+1}, y^{t+1}\right)}{D_{0}^{t}\left(x^{t}, y^{t}\right)}\left[\frac{D_{0}^{t}\left(x^{t+1}, y^{t+1}\right)}{D_{0}^{t+1}\left(x^{t+1}, y^{t+1}\right)} \frac{D_{0}^{t}\left(x^{t}, y^{t}\right)}{D_{0}^{t+1}\left(x^{t}, y^{t}\right)}\right]^{1 / 2}
$$

Or

$$
M=E . P
$$

where

$$
\begin{gathered}
E=\frac{D_{0}^{t+1}\left(x^{t+1}, y^{t+1}\right)}{D_{0}^{t}\left(x^{t}, y^{t}\right)} \\
P=\left[\frac{D_{0}^{t}\left(x^{t+1}, y^{t+1}\right)}{D_{0}^{t+1}\left(x^{t+1}, y^{t+1}\right)} \frac{D_{0}^{t}\left(x^{t}, y^{t}\right)}{D_{0}^{t+1}\left(x^{t}, y^{t}\right)}\right]^{1 / 2}
\end{gathered}
$$

Under the technical conditions of the T period, the efficiency change of the $t+1$ period compared with the $t$ period can be expressed as

$$
M^{t}=\frac{D^{t}\left(x_{t+1}, y_{t+1}\right)}{D^{t}\left(x_{t}, y_{t}\right)}
$$

Similarly, under the technical conditions of $t+1$, the efficiency change of $t+1$ compared with $t$ can be expressed as

$$
M^{t+1}=\frac{D^{t+1}\left(x_{t+1}, y_{t+1}\right)}{D^{t+1}\left(x_{t}, y_{t}\right)}
$$


The geometric mean of efficiency changes in the $t$ and $t+1$ periods and is used as the total factor productivity (Malmquist index) from the $t$ to the $t+1$ period. The formula is

$$
M\left(x_{t+1}, y_{t+1} ; x_{t}, y_{t}\right)=\sqrt{\frac{D^{t}\left(x_{t+1}, y_{t+1}\right)}{D^{t}\left(x_{t}, y_{t}\right)} \frac{D^{t+1}\left(x_{t+1}, y_{t+1}\right)}{D^{t+1}\left(x_{t}, y_{t}\right)}}
$$

By further splitting the above formula, the Malmquist index can be divided into the technical-efficiency (TE) and technological-progress (TP) indices. The technical-progress index refers to the promotion of the possible output under the given factor input through the introduction of more advanced production technology, reflecting the movement of the frontier of production technology in the period from $t$ to $t+1$. The details are

$$
\begin{aligned}
M\left(x_{t+1}, y_{t+1} ; x_{t}, y_{t}\right) & =\sqrt{\frac{D^{t}\left(x_{t+1}, y_{t+1}\right)}{D^{t}\left(x_{t}, y_{t}\right)} \frac{D^{t+1}\left(x_{t+1}, y_{t+1}\right)}{D^{t+1}\left(x_{t}, y_{t}\right)}} \\
& =\underbrace{\frac{D^{t+1}\left(x_{t+1}, y_{t+1}\right)}{D^{t}\left(x_{t}, y_{t}\right)}}_{\text {effch }} \times \underbrace{\sqrt{\frac{D^{t}\left(x_{t+1}, y_{t+1}\right)}{D^{t}\left(x_{t}, y_{t}\right)} \frac{D^{t+1}\left(x_{t}, y_{t}\right)}{D^{t+1}\left(x_{t}, y_{t}\right)}}}_{\text {techch }}
\end{aligned}
$$

The TE change index can be further decomposed into pure-technical-efficiency (PTE) and scale-efficiency (SE) changes, which are expressed as

$$
\begin{aligned}
& \text { effch }\left(x_{t+1}, y_{t+1} ; x_{t}, y_{t}\right)=\frac{D^{t}\left(x_{t}, y_{t} / \mathrm{CCR}\right)}{D^{t}\left(x_{t+1}, y_{t+1} / \mathrm{CCR}\right)} \\
& =\underbrace{\frac{D^{t}\left(x_{t}, y_{t} / \mathrm{BCC}\right)}{D^{t}\left(x_{t+1}, y_{t+1} / \mathrm{BCC}\right)}}_{\downarrow} \times \underbrace{\left[\frac{D^{t}\left(x_{t}, y_{t} / \mathrm{CCR}\right)}{D^{t}\left(x_{t+1}, y_{t+1} / \mathrm{CCR}\right)} \times \frac{D^{t}\left(x_{t+1}, y_{t+1} / \mathrm{BBC}\right)}{D^{t}\left(x_{t}, y_{t} / \mathrm{BBC}\right)}\right]}_{\downarrow} \\
& =\operatorname{pech}\left(x_{t+1}, y_{t+1} ; x_{t}, y_{t}\right) \times \operatorname{sech}\left(x_{t+1}, y_{t+1} ; x_{t}, y_{t}\right)
\end{aligned}
$$

The Malmquist index is finally expressed as TFP = PTE SE TE, which can be divided into the pure-technology-efficiency, scale-efficiency, and technology-progress indices. When TFP is more than 1, TFP improves; when TFP is less than 1, TFP declines; when TFP $=1$, TFP remains unchanged. The application of the Malmquist DEA in this paper had two main purposes: to analyze the total factor productivity of decision-making units and the change of efficiency, and to measure the contribution or influence of technological progress, pure technological efficiency, and scale efficiency on productivity.

\section{Variable Selection, Data Sources, and Sample}

\subsection{Input-Output Variables}

Input-output variables refer to existing studies and the availability of data, and the following variables were selected in this study (see Table 1). The first was the input index, which generally includes human, financial, and material resources. Human resources were evaluated in terms of personnel engaged in scientific and technological activities and full time equivalent personnel involved in research and development, which reflect, respectively, the necessary scale of human investment in scientific research activities and the actual amount of scientific research work being conducted. Financial resources were evaluated by the annual expenditure of university scientific research funds. Since the material resources of university scientific research are mainly represented by investment in infrastructure such as machinery and equipment, which are included in the internal expenditure of university scientific research funds, material resources were not considered separately. The second groups of variables were the output variables. The scientific research output of a university is mainly reflected in three aspects: the output of achievements, social benefits, and external influences. Indicators may include selection of a number of a scientific research projects, publishing papers, high level academic papers, monographs, and provincial level scientific research achievement evaluation indices, such as social benefits choosing the number, patent-technology transfer when actual income is the evaluation 
index, and co-operation with foreign research groups. International academic conferences attended formed part of the evaluation index.

Table 1. Input/output indicators of scientific research in universities.

\begin{tabular}{|c|c|c|}
\hline Scientific Research Input/Output & Name & Indicator \\
\hline \multirow{3}{*}{ Research input } & & Science and technology activities \\
\hline & Human resources & Full time equivalent for researchers and developers \\
\hline & Financial resources & $\begin{array}{l}\text { Internal expenditure of scientific research funds }=\text { labor fee }+ \\
\text { operating fee }+ \text { unit fee transferred out }+ \text { other funds }\end{array}$ \\
\hline \multirow{8}{*}{ Research output } & Scientific research projects & Number of scientific research projects approved in that year \\
\hline & & Total number of academic papers \\
\hline & Papers & High level academic papers \\
\hline & Monographs & Number of published books \\
\hline & Prize results & $\begin{array}{c}\text { Total research awards at or above provincial or } \\
\text { ministerial level }\end{array}$ \\
\hline & Patents & Number of patents granted \\
\hline & $\begin{array}{l}\text { Achievement } \\
\text { transformation }\end{array}$ & Actual income of technology transfer year $\left(\mathrm{Y}_{7}\right)$ \\
\hline & International co-operation & $\begin{array}{l}\text { Number of co-operative research dispatchers }\left(\mathrm{Y}_{8}\right) \\
\text { International academic conference attendance }\left(\mathrm{Y}_{9}\right)\end{array}$ \\
\hline
\end{tabular}

\subsection{External Environmental Variables}

External environmental variables are objective factors that can affect universities' scientific research efficiency but cannot be controlled by universities. The influence of external environmental factors must be included in consideration of the process of the relatively practical evaluation of university scientific research. [27] used the DEA-Tobit model in their research and showed that the research environment and regional education expenditures significantly affect input-output performance. The study of [28] showed that the regional economy, policy environment, and school-enterprise co-operation environment all substantially affect the input-output efficiency of scientific research in universities in different regions of China. Which environmental factors affect the scientific research efficiency of universities directly under the Ministry of Education? This study mainly studied influences on universities' scientific research efficiency from three aspects: policy, economy, and enterprise.

\subsubsection{Policy Support}

The government's policy support plays a prominent role in promoting the development of science and technology in universities. The government's support inevitably has different effects on the efficiency of scientific research. This paper chose to use the amount of government investment in scientific research funds to reflect local policies.

\subsubsection{Economic Level}

The regional economic development level is a key factor influencing the supply of scientific and technological funds and the demand factor of scientific and technological innovation in universities. It plays an essential supporting role in the construction of universities and the development of scientific research undertakings. It should be expected to be a crucial external influencing factor of scientific research efficiency in universities. This paper used GDP per capita to reflect the economic development level of each province.

\subsubsection{School-Enterprise Co-operation}

The co-operation between universities and enterprises is an important aspect of regional production, learning, and research strategy. Close relationships and collaboration between universities and enterprises play an important role in promoting scientific research output and achievement transformation of universities. Therefore, the amount of funding 
allocated by enterprises in the total amount of universities' scientific and technological funds was selected as the indicator of the school-enterprise co-operation environment.

\subsection{Data Description}

The data required for the present research were gathered from the compiled science and technology data of universities, compiled by the Department of Science and Technology of the Ministry of Education according to statistical data reported by the system at the end of each year. The data of external environment variables were taken from the compiled science and technology statistics of universities and the Chinese Statistical Yearbook (2012-2019). Economic level data were taken from the National Bureau of Statistics. The research institutions sampled in this paper were universities directly under the Ministry of Education, selected for the following reasons:

First, the studied universities were located in the four economic regions of central, eastern, western, and northeastern China. Second, in terms of representativeness, universities directly under the Ministry of Education's administration are directly managed by the Chinese Ministry of Education, leading the way in exploration and reform and playing an exemplary role in improving teaching quality, scientific research orientation, and social services [29]. Third, universities directly under the Ministry of Education include both comprehensive universities, such as Nanjing University, Fudan University, Tsinghua University, and polytechnic universities, such as the Dalian University of Technology and the East China University of Science. They also include business, regular class, political science and law, and agriculture universities, depending on the discipline [30]. Fourth, in terms of scientific research capacity, most of these universities have scientific research practices with a long history and profound knowledge. With a strong team of scholars, sufficient information resources, excellent experiment conditions, and a relatively standardized management system, their scientific research data were relatively comprehensive and representative.

This study selected 2010-2017 for empirical research samples from the country's 64 universities directly under the Ministry of Education. However, since the higher school science and technology statistical data collection includes only 64 scientific research universities directly under Ministry of Education statistics, as of May 2020, the report has not yet been officially released for 2019 out of consideration for availability and feasibility.

\section{Empirical Results}

\subsection{First Stage: BCC Model Results}

Based on input-output data from universities directly under the Ministry of Education from 2010 to 2017, the input-oriented BCC model was adopted, and DEAP 2.1 software was used to calculate the comprehensive technical efficiency, pure technical efficiency, and scale efficiency of scientific research in universities directly under the Ministry of Education. Results are shown in Table 2.

As can be seen from Table 2, without considering the influence of the external environment and random interferences, the average value of the overall technical efficiency of scientific research in universities directly under the Ministry of Education from 2010 to 2017 was 0.9289 , indicating that the gap in scientific research efficiency between universities was not large. The overall scientific research efficiency was relatively high. The average value of pure technical efficiency was 0.9447 , and the average value of scale efficiency was 0.9737. The performance of pure technical efficiency was worse than that of scale efficiency, indicating that the efficiency of scientific research management and innovation in Chinese universities should be promoted as a priority. Since the impacts of external environmental factors and random disturbances were not considered in this stage, these results could not reveal the actual level of scientific research productivity in universities directly under the Ministry of Education, so it was necessary to conduct more in depth adjustment and calculation. 
Table 2. First stage—technical efficiency, pure technical efficiency, and scale efficiency of scientific research in universities.

\begin{tabular}{|c|c|c|c|c|}
\hline University Name & Total Efficiency & $\begin{array}{c}\text { Pure Technical } \\
\text { Efficiency }\end{array}$ & Scale Efficiency & Return to Scale \\
\hline Peking University & 0.8993 & 0.9758 & 0.92 & IRS \\
\hline Renmin University of China & 0.9698 & 0.9859 & 0.9823 & DRS \\
\hline Tsinghua University & 1 & 1 & 1 & - \\
\hline Beijing Jiao Tong University & 1 & 1 & 1 & - \\
\hline University of Science and Technology Beijing & 0.7376 & 0.7905 & 0.9361 & IRS \\
\hline Beijing University of Chemical Technology & 0.9129 & 0.9305 & 0.9794 & IRS \\
\hline $\begin{array}{l}\text { Beijing University of Posts and } \\
\text { Telecommunications }\end{array}$ & 0.9583 & 0.9758 & 0.9814 & IRS \\
\hline China Agricultural University & 0.9988 & 0.999 & 0.9998 & IRS \\
\hline Beijing Forestry University & 0.9511 & 0.9824 & 0.9688 & IRS \\
\hline $\begin{array}{c}\text { Beijing University of Traditional Chinese } \\
\text { Medicine }\end{array}$ & 1 & 1 & 1 & - \\
\hline Beijing Normal University & 0.997 & 0.9998 & 0.9973 & IRS \\
\hline Communication University of China & 1 & 1 & 1 & - \\
\hline China University of Political Science and Law & 0.9375 & 1 & 0.9375 & IRS \\
\hline North China Electric Power University & 0.946 & 0.9469 & 0.9988 & IRS \\
\hline Nankai University & 0.924 & 0.9456 & 0.977 & DRS \\
\hline Tianjin University & 0.9366 & 0.9724 & 0.963 & IRS \\
\hline Dalian University of Technology & 0.7559 & 0.7919 & 0.9548 & IRS \\
\hline Northeastern University & 0.9729 & 0.9976 & 0.9748 & IRS \\
\hline Jilin University & 0.6745 & 0.8485 & 0.7883 & IRS \\
\hline Northeast Normal University & 0.885 & 0.9015 & 0.981 & DRS \\
\hline Northeast Forestry University & 1 & 1 & 1 & - \\
\hline Fudan University & 1 & 1 & 1 & - \\
\hline Tongji University & 0.8869 & 0.9565 & 0.926 & IRS \\
\hline Shanghai Jiao Tong University & 1 & 1 & 1 & - \\
\hline $\begin{array}{c}\text { East China University of Science and } \\
\text { Technology }\end{array}$ & 0.9846 & 0.9885 & 0.996 & IRS \\
\hline Donghua University & 0.8495 & 0.8568 & 0.9914 & IRS \\
\hline East China Normal University & 0.8088 & 0.8181 & 0.9883 & IRS \\
\hline Nanjing University & 1 & 1 & 1 & - \\
\hline Southeast University & 0.9976 & 1 & 0.9976 & IRS \\
\hline China University of Mining and Technology & 0.9941 & 1 & 0.9941 & IRS \\
\hline Hohai University & 0.9755 & 0.9964 & 0.9785 & IRS \\
\hline Jiangnan University & 1 & 1 & 1 & - \\
\hline Nanjing Agricultural University & 0.7034 & 0.7223 & 0.9719 & IRS \\
\hline China Pharmaceutical University & 0.869 & 0.8885 & 0.9769 & IRS \\
\hline Zhejiang University & 0.9916 & 1 & 0.9916 & IRS \\
\hline Hefei University of Technology & 0.9493 & 0.9516 & 0.9971 & DRS \\
\hline Xiamen University & 0.9765 & 0.9811 & 0.9945 & IRS \\
\hline Shandong University & 0.8998 & 0.9658 & 0.9296 & IRS \\
\hline Ocean University of China & 0.974 & 0.9805 & 0.9923 & IRS \\
\hline China University of Petroleum (East China) & 0.8273 & 0.8836 & 0.9403 & IRS \\
\hline Wuhan University & 0.949 & 1 & 0.949 & IRS \\
\hline $\begin{array}{l}\text { Huazhong University of Science and } \\
\text { Technology }\end{array}$ & 0.8651 & 0.9963 & 0.8685 & IRS \\
\hline China University of Geosciences (Wuhan) & 0.9731 & 0.9796 & 0.9935 & IRS \\
\hline Wuhan University of Technology & 0.854 & 0.919 & 0.9285 & IRS \\
\hline Huazhong Agricultural University & 0.9453 & 0.9494 & 0.9944 & IRS \\
\hline Central China Normal University & 0.9586 & 0.9719 & 0.986 & IRS \\
\hline Hunan University & 0.628 & 0.6323 & 0.9934 & IRS \\
\hline Central South University & 0.9763 & 1 & 0.9763 & IRS \\
\hline Sun Yat-Sen University & 0.9256 & 0.9876 & 0.9359 & IRS \\
\hline South China University of Technology & 1 & 1 & 1 & - \\
\hline Sichuan University & 0.9155 & 0.9978 & 0.9173 & IRS \\
\hline
\end{tabular}


Table 2. Cont.

\begin{tabular}{|c|c|c|c|c|}
\hline University Name & Total Efficiency & $\begin{array}{l}\text { Pure Technical } \\
\text { Efficiency }\end{array}$ & Scale Efficiency & Return to Scale \\
\hline Chongqing University & 0.9578 & 0.9675 & 0.9894 & IRS \\
\hline Southwest Jiao Tong University & 1 & 1 & 1 & - \\
\hline University of Electronic Science and Technology & 0.8304 & 0.8524 & 0.9729 & IRS \\
\hline Southwest University & 0.9009 & 0.9393 & 0.9608 & IRS \\
\hline $\mathrm{Xi}^{\prime}$ an Jiao Tong University & 0.9383 & 0.9765 & 0.9599 & IRS \\
\hline Xidian University & 0.8573 & 0.878 & 0.9789 & IRS \\
\hline Changan University & 1 & 1 & 1 & - \\
\hline $\begin{array}{c}\text { Northwest University of Science and } \\
\text { Technology }\end{array}$ & 0.5405 & 0.5788 & 0.943 & IRS \\
\hline Shaanxi Normal University & 0.9805 & 0.9895 & 0.9904 & IRS \\
\hline Lanzhou University & 1 & 1 & 1 & - \\
\hline $\begin{array}{l}\text { China University of Mining and Technology } \\
\text { (Beijing) }\end{array}$ & 1 & 1 & 1 & - \\
\hline China University of Petroleum (Beijing) & 0.9089 & 0.9183 & 0.9884 & IRS \\
\hline China University of Geosciences (Beijing) & 0.8838 & 0.8964 & 0.9841 & IRS \\
\hline Mean & 0.9208 & 0.9447 & 0.9737 & \\
\hline
\end{tabular}

TE indicates total (overall) efficiency; PTE indicates pure technical efficiency, and SE indicates scale efficiency, respectively. 'IRS' indicates increasing return to scale; 'DRS' indicates decreasing return to scale and '- ' indicates constant (no change) return to scale, respectively.

\subsection{Second Stage-Similar SFA Regression Results}

In this section, redundant values of the input variables obtained from DEA in the first stage were taken as the explained variables, and policy support (government input), schoolenterprise co-operation (the amount of funds allocated by universities), and economic level (per capita GDP) were taken as the explanatory variables. The following stochastic frontier model was established:

$$
\text { S_it }=\llbracket \beta \_0+X \rrbracket \_ \text {it } \beta+\left(V \_i t-U \_i t\right), i=1,2, \ldots, 6, t=1,2, \ldots, 15,
$$

where $S_{-}$it is the amount of relaxation, and $X_{-}$it is each environmental variable.

Frontier 4.1 software was used to carry out quantitative regression analysis using the SFA model. The original values of each input variable were adjusted according to the regression results to eliminate the influence of environmental and random interference factors. The regression results are shown in Table 3. The statistic scores of the LR unilateral test were all greater than the corresponding critical value, indicating that the SFA model was reasonably set.

Table 3. Stochastic-frontier method (SFA) regression results of redundant input variables.

\begin{tabular}{|c|c|c|c|}
\hline Independent Variable & $\begin{array}{l}\text { Redundant Staff for Science } \\
\text { and Technology Activities }\end{array}$ & $\begin{array}{l}\text { Full-Time R\&D } \\
\text { Redundancy }\end{array}$ & $\begin{array}{l}\text { Internal Expenditure of } \\
\text { R\&D Fund Redundancy }\end{array}$ \\
\hline Constant & 45.1432 & -76.4866 & $-24,994.8700 * * *$ \\
\hline Policy support (government input) & $0.00011^{* *}$ & $0.00014^{* * *}$ & $0.0321 * *$ \\
\hline $\begin{array}{l}\text { School-enterprise co-operation (amount of capital } \\
\text { allocated by enterprises) }\end{array}$ & -0.00016 & -0.00013 & 0.0558 * \\
\hline $\begin{array}{c}\text { Economic level (per capita GDP, ten thousand } \\
\text { yuan/person) }\end{array}$ & $-33.1674^{* * *}$ & $-21.6135^{* * *}$ & $-7451.8579 * * *$ \\
\hline Sigma-squared & $725,441 * * *$ & $740,033.90^{* * *}$ & $32,920,192,000 * * *$ \\
\hline Gamma & $0.84512^{* * *}$ & $0.9129 * * *$ & $0.5521^{* * *}$ \\
\hline Log-likelihood function & -3774.8758 & -3647.7515 & -6768.0884 \\
\hline LR test of one-sided error & 420.6597 & 633.5522 & 105.3631 \\
\hline
\end{tabular}

$* * *, * *$ and $*$ indicate that corresponding variables are significant at significance levels of $1 \%, 5 \%$, and $10 \%$, respectively.

In the second stage, the explained variable of the regression model was input redundancy. If the regression coefficient of an environmental variable was positive, then increasing the environmental variable increased the input redundancy of universities, 
which is not conducive to the improvement of scientific research efficiency. On the other hand, when the regression coefficient of an environmental variable was negative, increasing the environmental variable reduced universities' investment redundancy, so it tended to improve the efficiency of scientific research. As can be seen from the regression results, the directions of each environmental variable on the redundancy of the three inputs were the same.

First, regression coefficients of the government investment amount on the three slack variables were all positive, which reflected the government's great investment in and support of the scientific research funds of universities directly under the Ministry of Education, but also led to a waste of their scientific research investment resources. The reason for this may be that universities directly under the Ministry of Education are more likely to receive financial support from government departments thanks to advantages such as a long history, profound knowledge, and excellent experimental conditions. Easy access to resources may make universities disregard efficiency in terms of their rational allocation and use. Second, research of enterprise capital support through scientific research personnel without redundancy, and research and development of full time staff were redundant regression equations. Within $R \& D$ spending, redundancy in the regression equation reached a $10 \%$ level of significance, and if the coefficient is positive, this would reflect that co-operation with enterprise on scientific research in universities directly under the Ministry of Education enhances the efficiency of scientific research in universities. This result not only failed to promote this role, but also had a significant negative impact. The reason may be that, due to the enterprise and co-operation of universities directly under the Ministry of Education outside of innovation related to internal university resources, the universities' innovation was suppressed [31].

Third, regression coefficients of per capita GDP on the three slack variables were all negative, indicating that the higher the economic development level is, the more easily a region can attract scientific research talent, and the lower the redundancy of R\&D investment in a university, the higher the scientific research efficiency is. The above analysis showed that the influence of external environmental factors on the resource inputs of universities directly under the Ministry of Education cannot be ignored. If this is not taken into account in the efficiency model, estimated results may not truly reflect the scientific research management level of universities directly under the Ministry of Education. More importantly, the comparison of scientific research efficiency in universities directly under the Ministry of Education should be based on the same external environment and state, to ensure that the comparisons have practical significance and value. Therefore, to eliminate the influence of different environmental factors and random interferences from the input, it was necessary to adjust the input variables.

\subsection{Third Stage-BCC Model Results after Adjusting Input}

The original input variable was adjusted according to the regression results of SFA variables as the new input variable, and the primary output variable remained the output variable. The traditional DEA model was used once again for efficiency calculation, and the scientific research efficiency value of the adjusted variable was obtained. See Table 4 for details. 
Table 4. Scientific research efficiency of universities without influence of environmental factors.

\begin{tabular}{|c|c|c|c|c|}
\hline University Name & Total Efficiency & $\begin{array}{l}\text { Pure Technical } \\
\text { Efficiency }\end{array}$ & Scale Efficiency & Return to Scale \\
\hline Peking University & 1 & 1 & 1 & - \\
\hline Renmin University of China & 0.9838 & 1 & 0.9838 & IRS \\
\hline Tsinghua University & 1 & 1 & 1 & - \\
\hline Beijing Jiao Tong University & 0.9163 & 1 & 0.9163 & IRS \\
\hline University of Science and Technology Beijing & 0.7978 & 0.9875 & 0.8049 & IRS \\
\hline Beijing University of Chemical Technology & 0.3035 & 0.9936 & 0.3058 & IRS \\
\hline $\begin{array}{l}\text { Beijing University of Posts and } \\
\text { Telecommunications }\end{array}$ & 0.6656 & 0.9988 & 0.6661 & IRS \\
\hline China Agricultural University & 0.8485 & 1 & 0.8485 & IRS \\
\hline Beijing Forestry University & 0.6836 & 0.9998 & 0.6838 & IRS \\
\hline $\begin{array}{c}\text { Beijing University of Traditional Chinese } \\
\text { Medicine }\end{array}$ & 1 & 1 & 1 & - \\
\hline Beijing Normal University & 0.9948 & 1 & 0.9948 & IRS \\
\hline Communication University of China & 0.5059 & 0.9953 & 0.5074 & IRS \\
\hline China University of Political Science and Law & 0.802 & 1 & 0.802 & IRS \\
\hline North China Electric Power University & 0.4788 & 0.9918 & 0.4821 & IRS \\
\hline Nankai University & 0.9919 & 1 & 0.9919 & IRS \\
\hline Tianjin University & 0.8561 & 1 & 0.8561 & IRS \\
\hline Dalian University of Technology & 0.7276 & 0.9998 & 0.7279 & IRS \\
\hline Northeastern University & 0.995 & 1 & 0.995 & IRS \\
\hline Jilin University & 0.9003 & 1 & 0.9003 & IRS \\
\hline Northeast Normal University & 0.7166 & 1 & 0.7166 & IRS \\
\hline Northeast Forestry University & 0.6294 & 1 & 0.6294 & IRS \\
\hline Fudan University & 1 & 1 & 1 & - \\
\hline Tongji University & 0.9554 & 1 & 0.9554 & IRS \\
\hline Shanghai Jiao Tong University & 1 & 1 & 1 & - \\
\hline $\begin{array}{c}\text { East China University of Science and } \\
\text { Technology }\end{array}$ & 0.5594 & 1 & 0.5594 & IRS \\
\hline Donghua University & 0.3686 & 0.9894 & 0.3724 & IRS \\
\hline East China Normal University & 0.613 & 1 & 0.613 & IRS \\
\hline Nanjing University & 0.8883 & 1 & 0.8883 & IRS \\
\hline Southeast University & 0.7825 & 0.9879 & 0.793 & IRS \\
\hline China University of Mining and Technology & 0.7618 & 0.9986 & 0.7628 & IRS \\
\hline Hohai University & 0.6713 & 1 & 0.6713 & IRS \\
\hline Jiangnan University & 0.7934 & 1 & 0.7934 & IRS \\
\hline Nanjing Agricultural University & 0.6811 & 1 & 0.6811 & IRS \\
\hline China Pharmaceutical University & 0.512 & 1 & 0.512 & IRS \\
\hline Zhejiang University & 1 & 1 & 1 & - \\
\hline Hefei University of Technology & 0.7449 & 1 & 0.7449 & IRS \\
\hline Xiamen University & 0.7518 & 1 & 0.7518 & IRS \\
\hline Shandong University & 0.8928 & 1 & 0.8928 & IRS \\
\hline Ocean University of China & 0.8824 & 1 & 0.8824 & IRS \\
\hline China University of Petroleum (East China) & 0.7304 & 0.9803 & 0.7411 & IRS \\
\hline Wuhan University & 0.9965 & 1 & 0.9965 & IRS \\
\hline $\begin{array}{c}\text { Huazhong University of Science and } \\
\text { Technology }\end{array}$ & 0.9909 & 1 & 0.9909 & IRS \\
\hline China University of Geosciences (Wuhan) & 0.821 & 1 & 0.821 & IRS \\
\hline Wuhan University of Technology & 0.6409 & 0.9981 & 0.6419 & IRS \\
\hline Huazhong Agricultural University & 0.7175 & 1 & 0.7175 & IRS \\
\hline Central China Normal University & 0.9066 & 1 & 0.9066 & IRS \\
\hline Hunan University & 0.5483 & 0.9993 & 0.5485 & IRS \\
\hline Central South University & 1 & 1 & 1 & - \\
\hline Sun Yat-Sen University & 1 & 1 & 1 & - \\
\hline
\end{tabular}


Table 4. Cont.

\begin{tabular}{|c|c|c|c|c|}
\hline University Name & Total Efficiency & $\begin{array}{c}\text { Pure Technical } \\
\text { Efficiency }\end{array}$ & Scale Efficiency & Return to Scale \\
\hline South China University of Technology & 0.8834 & 1 & 0.8834 & IRS \\
\hline Sichuan University & 0.9965 & 1 & 0.9965 & IRS \\
\hline Chongqing University & 0.6198 & 1 & 0.6198 & IRS \\
\hline Southwest Jiao Tong University & 0.9929 & 1 & 0.9929 & IRS \\
\hline University of Electronic Science and Technology & 0.5825 & 0.985 & 0.5914 & IRS \\
\hline Southwest University & 0.8034 & 1 & 0.8034 & IRS \\
\hline Xian Jiao tong University & 0.7869 & 1 & 0.7869 & IRS \\
\hline Xidian University & 0.5623 & 0.9985 & 0.5633 & IRS \\
\hline Changan University & 0.6194 & 1 & 0.6194 & IRS \\
\hline $\begin{array}{c}\text { Northwest A and F University of Science and } \\
\text { Technology }\end{array}$ & 0.5899 & 0.9998 & 0.59 & IRS \\
\hline Shaanxi Normal University & 0.5791 & 1 & 0.5791 & IRS \\
\hline Lanzhou University & 0.8284 & 1 & 0.8284 & IRS \\
\hline $\begin{array}{c}\text { China University of Mining and Technology } \\
\text { (Beijing) }\end{array}$ & 0.9339 & 1 & 0.9339 & IRS \\
\hline China University of Petroleum (Beijing) & 0.8031 & 1 & 0.8031 & IRS \\
\hline China University of Geosciences (Beijing) & 0.8516 & 1 & 0.8516 & IRS \\
\hline Mean & 0.7881 & 0.9985 & 0.7889 & \\
\hline
\end{tabular}

TE indicates total (overall) efficiency; PTE indicates pure technical efficiency, and SE indicates scale efficiency, respectively. 'IRS' indicates increasing return to scale; 'DRS' indicates decreasing return to scale and '- indicates constant (no change) return to scale, respectively.

Comparing the efficiency values after and before adjustment, it was found that the scientific research efficiency values of most universities had changed. The average value of comprehensive technical efficiency decreased from 0.9289 before adjustment to 0.7881 , indicating large gaps in scientific research efficiency among universities. Some universities had low scientific research efficiency. The average value of pure technical efficiency increased from 0.9447 before adjustment to 0.9985 , and the average value of scale efficiency decreased from 0.9737 before adjustment to 0.7889 . The score of scale efficiency was much lower than that at the first stage, indicating that the lack of scale efficiency was the main factor restricting the improvement of Chinese universities' scientific research efficiency. From the point of view of the individual decision-making units, of the 64 universities (Peking University, Renmin University of China, Beijing University of Science and Technology, Nankai University, Northeastern University, Jilin University, Tongii University, Zhejiang University, Wuhan University, Huazhong University of Science and Technology, South-Central University, Sun Yat-Sen University, Sichuan University, Northwest Agriculture and Forestry University of Science and Technology, etc.), the overall efficiencies of fourteen universities, including Tsinghua University, Beijing University of Chinese Medicine, Fudan University, and Shanghai Jiaotong University increased; four comprehensive efficiencies remained unchanged; and the comprehensive efficiencies of other universities were reduced. The most noteworthy result was that the three efficiency scores of Peking University were all increased after adjustment, indicating that the R\&D efficiency of Peking University was underestimated due to the influence of environmental variables and random disturbance factors. In the Communication University of China, on the other hand, the real R\&D efficiency of the third stage was only 0.5059 after the second stage; the R\&D efficiency of the first stage was greatly overestimated. This shows that environmental variables and random factors have a significant impact on China's scientific research efficiency. Again, this also highlights the significance of selecting a three stage DEA model.

The comparison results of the overall efficiency of the first and third stages are shown in Figure 1. It can be seen that the efficiency value of the first stage was quite different than that of the third stage. In the first stage, before investment adjustment, the scientific research efficiency of universities in China tended to increase year by year. In contrast, the third stage tended to oscillate. On the surface, the utilization of scientific-research 
resources in universities was increasing year by year, but this is only a false impression of "superficial prosperity". Environmental variables and random-disturbance factors cover the real input-output efficiency relationship, and overall scientific-research efficiency was overestimated by the traditional CCR and BCC models.

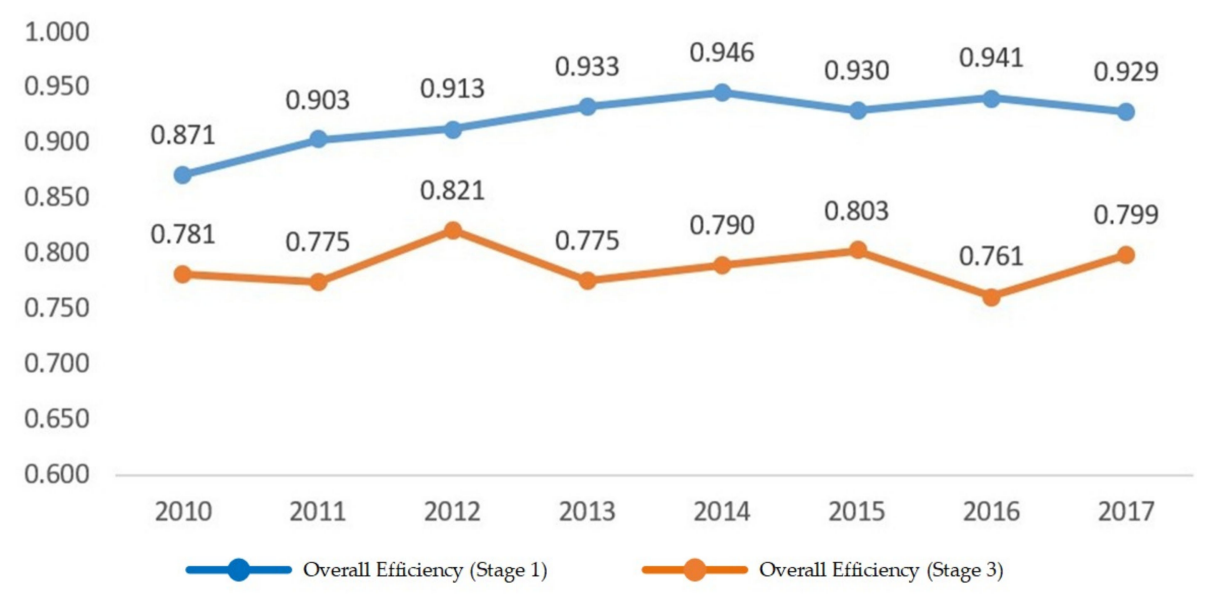

Figure 1. Comparison of comprehensive efficiency before and after input adjustment.

\subsection{Dynamic Trend Analysis of University Scientific Research Input-Output in 2010-2017}

The three preceding sections describe the use of the DEA method to analyze the static efficiency of the input-output of scientific research in universities directly under the Ministry of Education from 2010 to 2017. The efficiency of each decision-making unit could not be compared vertically, so to investigate the dynamic changes of efficiency of each decision-making unit, this study used DEAP2.1 software to analyze the Malmquist total factor productivity index (TFP) and its decomposable items, i.e., the panel data of scientific research input and output of 64 universities. A TFP score greater than 1 indicated an increase in research efficiency, while a score less than 1 indicated a decline in research efficiency. TFP was decomposed into the technical-efficiency change (TE) and the technical-progress (TP) indices, and TE was further decomposed into the pure-technicalefficiency (PTE) and scale-efficiency (SE) change indices. Among these indices, the pure technical efficiency of university scientific research measures the efficiency of university scientific research influenced by management and innovation, the efficiency of university scientific research scale is the efficiency of university scientific research brought about by the investment scale, and technological progress reflects the movement of the front of the two periods of production. Like the total factor productivity index, the decomposition item score was more than 1 , which indicated the improvement of university scientific research efficiency, and vice versa, which suggested the decline of university scientific research efficiency.

According to the overall average change level of scientific research efficiency of universities shown in Table 5, the overall average value of the Malmquist index of 64 universities directly under the Ministry of Education in China from 2010 to 2017 was 1.037; only in 2014 and 2016 was the Malmquist index less than 1, which indicates that the utilization efficiency of scientific research resources in universities directly under the Ministry of Education is increasing. From the perspective of the decomposition index, the average change index of the technical efficiency of the scientific research activities of the studied universities was 1.039, while the average change in technical progress is 0.998; only in 2011 and 2013 and 2015 was it more than 1, which indicated that the change index of technological progress less than 1 had a slightly negative effect on the improvement of scientific research efficiency in universities directly under the Ministry of Education. By further decomposing the technical-efficiency index, it was found that the change of pure technical efficiency and the growth of scale efficiency were both factors of technical efficiency improvement. The average growth rates were $0.1 \%$ and $3.8 \%$, respectively, over 
the eight years; scale optimization is the main internal factor that promotes the efficiency of scientific research in Chinese universities.

Table 5. Malmquist and mean decomposition indices of universities in different years.

\begin{tabular}{cccccc}
\hline Year & TE & TP & PTE & SE & TFP \\
\hline $2010-2011$ & 1.071 & 1.073 & 1.007 & 1.064 & 1.15 \\
$2011-2012$ & 1.116 & 0.899 & 1 & 1.116 & 1.004 \\
$2012-2013$ & 0.942 & 1.087 & 1 & 0.942 & 1.023 \\
$2013-2014$ & 1.102 & 0.902 & 1 & 1.102 & 0.993 \\
$2014-2015$ & 1.011 & 1.117 & 1 & 1.011 & 1.129 \\
$2015-2016$ & 0.955 & 0.991 & 1 & 0.955 & 0.947 \\
$2016-2017$ & 1.092 & 0.941 & 1 & 1.092 & 1.028 \\
Mean & 1.039 & 0.998 & 1.001 & 1.038 & 1.037 \\
\hline
\end{tabular}

TE indicates total (overall) efficiency; TP indicates technical-progress index; PTE indicates pure technical efficiency; SE indicates scale efficiency; TFP indicates total factor productivity, respectively.

As shown in Table 6, from 2010 to 2017, there was an increase in the Malmquist total factor productivity index (TFP) of scientific research activities in 48 of 64 universities directly under the Ministry of Education, accounting for $75.0 \%$ of the total. The biggest increase was in Shaanxi Normal University, where the growth was $14.9 \%$. Other universities with increases of more than $10 \%$ were China University of Mining, Beijing University of Chemical Technology, Changan University, Renmin University of China, River Sea University, China University of Mining (Beijing), and China University of Petroleum, with the smallest increase being in Wuhan University, an increase rate of only $1.0 \%$. Further analysis showed that only nine universities had scores of less than 1 in scale-efficiency change. Once again, the main reason for the improvement of research efficiency was the improvement of scale efficiency. During the study period, Wuhan University's total factor productivity index was 1 , and all decomposition measures were equivalent to 1 . Of the 15 universities with a total factor productivity index of less than 1, the worst performing was Beijing Forestry University, which scored 0.897 on total factor productivity; in addition to pure technical efficiency, the other decomposition items were all less than 1, and the technology-progress index performed the worst, with only 0.924 .

Table 6. Average Malmquist indices for scientific research activities of universities in 2010-2017.

\begin{tabular}{|c|c|c|c|c|c|}
\hline University Name & TE & TP & PTE & SE & TFP \\
\hline Peking University & 1.022 & 1.005 & 1.005 & 1.016 & 1.027 \\
\hline Renmin University of China & 1.184 & 0.942 & 1.002 & 1.182 & 1.116 \\
\hline Tsinghua University & 1 & 0.991 & 1 & 1 & 0.991 \\
\hline Beijing Jiao Tong University & 1.071 & 1.007 & 1 & 1.071 & 1.079 \\
\hline University of Science and Technology Beijing & 1.088 & 0.96 & 1.015 & 1.072 & 1.044 \\
\hline Beijing University of Chemical Technology & 1.107 & 1.01 & 1.006 & 1.1 & 1.118 \\
\hline Beijing University of Posts and Telecommunications & 0.929 & 0.973 & 1 & 0.929 & 0.904 \\
\hline China Agricultural University & 1.071 & 1.01 & 1.002 & 1.069 & 1.082 \\
\hline Beijing Forestry University & 0.97 & 0.924 & 1 & 0.97 & 0.897 \\
\hline Beijing University of Traditional Chinese Medicine & 1.058 & 0.96 & 1 & 1.058 & 1.016 \\
\hline Beijing Normal University & 1.068 & 0.964 & 1.007 & 1.06 & 1.03 \\
\hline Communication University of China & 1.055 & 0.993 & 1.007 & 1.047 & 1.047 \\
\hline China University of Political Science and Law & 0.963 & 0.99 & 1.001 & 0.961 & 0.954 \\
\hline North China Electric Power University & 1.179 & 0.932 & 1.009 & 1.169 & 1.099 \\
\hline Nankai University & 1.04 & 0.945 & 1.011 & 1.029 & 0.983 \\
\hline Tianjin University & 1.066 & 1.023 & 1.001 & 1.065 & 1.091 \\
\hline Dalian University of Technology & 1.055 & 1.022 & 1 & 1.055 & 1.078 \\
\hline Northeastern University & 1.006 & 1.046 & 1 & 1.006 & 1.052 \\
\hline
\end{tabular}


Table 6. Cont.

\begin{tabular}{|c|c|c|c|c|c|}
\hline University Name & TE & TP & PTE & SE & TFP \\
\hline Jilin University & 1 & 1.022 & 1 & 1 & 1.022 \\
\hline Northeast Normal University & 1.073 & 0.99 & 1 & 1.073 & 1.062 \\
\hline Northeast Forestry University & 1.07 & 0.995 & 1 & 1.07 & 1.065 \\
\hline Fudan University & 1.036 & 1.033 & 1 & 1.036 & 1.07 \\
\hline Tongji University & 1 & 1.057 & 1 & 1 & 1.057 \\
\hline Shanghai Jiao Tong University & 1 & 0.985 & 1 & 1 & 0.985 \\
\hline East China University of Science and Technology & 1.008 & 1.017 & 1 & 1.008 & 1.025 \\
\hline Donghua University & 0.964 & 1.012 & 1 & 0.964 & 0.976 \\
\hline East China Normal University & 1.008 & 0.936 & 1 & 1.008 & 0.944 \\
\hline Nanjing University & 1.027 & 1.062 & 1 & 1.027 & 1.09 \\
\hline Southeast University & 1 & 1.042 & 1 & 1 & 1.042 \\
\hline China University of Mining and Technology & 1.092 & 1.036 & 1 & 1.092 & 1.131 \\
\hline Hohai University & 1.083 & 1.03 & 1 & 1.083 & 1.115 \\
\hline Jiangnan University & 1 & 1.014 & 1 & 1 & 1.014 \\
\hline Nanjing Agricultural University & 1.101 & 0.948 & 1 & 1.101 & 1.044 \\
\hline China Pharmaceutical University & 1.093 & 0.973 & 1 & 1.093 & 1.064 \\
\hline Zhejiang University & 1 & 1.016 & 1 & 1 & 1.016 \\
\hline Hefei University of Technology & 1.051 & 1.019 & 1 & 1.051 & 1.071 \\
\hline Xiamen University & 0.922 & 1.043 & 1 & 0.922 & 0.961 \\
\hline Shandong University & 0.993 & 1.015 & 1 & 0.993 & 1.008 \\
\hline Ocean University of China & 0.998 & 0.901 & 1 & 0.998 & 0.9 \\
\hline China University of Petroleum (East China) & 1.076 & 1.029 & 1 & 1.076 & 1.108 \\
\hline Wuhan University. & 1 & 1 & 1 & 1 & 1 \\
\hline Huazhong University of Science and Technology & 1.009 & 1.016 & 1 & 1.009 & 1.025 \\
\hline China University of Geosciences (Wuhan) & 1.058 & 1.01 & 1 & 1.058 & 1.069 \\
\hline Wuhan University of Technology & 1.054 & 1.014 & 1 & 1.054 & 1.069 \\
\hline Huazhong Agricultural University & 1.086 & 0.984 & 1 & 1.086 & 1.07 \\
\hline Central China Normal University & 1.046 & 0.971 & 1 & 1.046 & 1.015 \\
\hline Hunan University & 0.978 & 0.989 & 1 & 0.978 & 0.967 \\
\hline Central South University & 1.005 & 0.963 & 1 & 1.005 & 0.968 \\
\hline Sun Yat-Sen University & 1 & 0.972 & 1 & 1 & 0.972 \\
\hline South China University of Technology & 1 & 1.012 & 1 & 1 & 1.012 \\
\hline Sichuan University & 1 & 1.03 & 1 & 1 & 1.03 \\
\hline Chongqing University & 1.014 & 1.028 & 1 & 1.014 & 1.042 \\
\hline Southwest Jiao Tong University & 1 & 0.912 & 1 & 1 & 0.912 \\
\hline University of Electronic Science and Technology & 1.075 & 0.996 & 1 & 1.075 & 1.07 \\
\hline Southwest University & 1.089 & 0.993 & 1 & 1.089 & 1.081 \\
\hline Xi'an Jiao tong University & 1.039 & 1.033 & 1 & 1.039 & 1.073 \\
\hline Xidian University & 1.083 & 1.012 & 1 & 1.083 & 1.096 \\
\hline Changan University & 1.101 & 1.015 & 1 & 1.101 & 1.118 \\
\hline $\begin{array}{c}\text { Northwest A and F University of Science and } \\
\text { Technology }\end{array}$ & 1.045 & 1.034 & 1 & 1.045 & 1.08 \\
\hline Shaanxi Normal University & 1.107 & 1.037 & 1 & 1.107 & 1.149 \\
\hline Lanzhou University & 0.981 & 1.009 & 1 & 0.981 & 0.99 \\
\hline China University of Mining and Technology (Beijing) & 1.117 & 0.993 & 1 & 1.117 & 1.109 \\
\hline China University of Petroleum (Beijing) & 1.126 & 0.973 & 1 & 1.126 & 1.096 \\
\hline China University of Geosciences (Beijing) & 1.046 & 1.045 & 1 & 1.046 & 1.094 \\
\hline Mean & 1.039 & 0.998 & 1.001 & 1.038 & 1.037 \\
\hline
\end{tabular}

TE indicates total (overall) efficiency; TP indicates technical-progress index; PTE indicates pure technical efficiency; SE indicates scale efficiency; TFP indicates total factor productivity, respectively.

\subsection{Discussion}

Higher education institutions are the primary sources to produce high-level innovative talents and the main reference to solve scientific and technological issues, and enhance research outputs. Moreover, higher institutions' universities' initiatives towards scientific research activities are essential to expand social and pure science research scope and catalyze social and economic development [14]. Therefore, considering this study motivates 
the examination of the scientific research output of Chinese universities that are directly reported and monitored by the Ministry of education covered the period of 2010-2017. For this examination, this study used human resources and financial resources as scientific research inputs and scientific research projects, papers, monographs, prize results, patents, achievement transformation, and international cooperation as outputs. Additionally, the study considered external environmental factors, including policy support, economic level, and school-enterprise co-operation, which can affect research output.

After evaluating the scientific research output of 64 higher education institutions, universities, based on the three-stage DEA and Malmquist index method, this study offers some interesting facts and implications for further advancement of research output. First, after and before adjustment, most universities' scientific research efficiency values had changed and showed an increasing trend. The overall average value of the Malmquist index was 1.037; except in 2014 and 2016 was the Malmquist index was less than 1, which indicates that the utilization efficiency of scientific research resources in universities is increasing. Considering that the average growth rates of the overall sampled were presenting a growing trend, from $0.1 \%$ and $3.8 \%$, scale optimization is the primary internal factor that promotes the efficiency of scientific research in Chinese universities over the years. The study findings and implications are in line with and extend the analysis of [32] and offer a new research direction to promote and sustain the research output of higher institutions. For example, universities should establish a comprehensive evaluation system that monitors the development, creates possible ease to take new initiatives, emphasizes quality output and achievements, etc. Additionally, universities and government departments should expand their established partnerships with other national and global institutions to promote science commercialization, eventually; these involvements and implementations will improve research outputs and sustainability globally.

\section{Conclusions}

This study examined the static and dynamic efficiency of scientific research output of universities directly monitored by the Ministry of Higher Education, China. For instance, the study used a novel set of observations and applied advanced methodological techniques to examine sampled universities' research output and reported new insights. Based on the analysis, we draw the following conclusions:

First, the three stage DEA model is more efficient to measure the scientific research efficiency of universities directly under the Ministry of Education. Additionally, after adjustments of environmental factors, the correlation between the efficiency of scientific research in universities and the Spearman rating of scientific research output significantly improved, indicating that environmental factors and random errors in universities have significant impacts on the efficiency of scientific research.

Second, the three environmental factors assessed in this research had different types of significant impact on redundant scientific research investments of universities. Regional economic development level had a significant negative influence on unnecessary workforce and expenditure on scientific research. The policy environment had a significant positive effect on the redundancy of the research workforce and spending. Finally, the influence of a school-enterprise co-operation environment on human-resource redundancy was only directional, without substantial support, and had a significant positive impact on the monotony of the fund input. These findings show that in optimizing the efficiency of scientific research in universities, the external environment is creating issues that need a remedial measure: the control of universities should be based on the effects of environmental factors on the efficiency of scientific research, make full use of government and enterprise funds, strengthen the co-operation of universities and enterprises, and boost universities to promote the efficiency of scientific research. At the same time, from the perspective of government supervision, universities should pay special attention to the use of human and financial resources. 
Third, as shown by the decomposed efficiency value about the efficiency of scientific research in universities characteristics, some universities had high pure technical and scale efficiency. Universities should adjust to local conditions when taking steps to improve their pure technical efficiency and scale efficiency. Universities with lower pure technical efficiency should start with management ideas and methods of innovating scientific research. Universities lacking in scale efficiency need to expand their existing scientific research program to promote their overall scientific research scale.

Fourth, in terms of dynamic change trends, the average value of the Malmquist index of input-output efficiency of scientific research activities of universities in China from 2010 to 2017 was 1.037, which indicates that the scientific research performance of universities presented an increasing trend. The average Malmquist index of 48 universities was more significant than 1 in 2010-2017, and about 75\% of the universities showed an improved trend in research efficiency. Considering decomposition index, the average value of the size of universities was 1.038. The average value of the technological progress index was 0.998 . Among the studied universities, $52 \%$ had a technological-progress index lower than 1 ; this also shows that the improvement of scale efficiency promotes universities' scientific research efficiency, while weak progress of technology hinders efficiency. At the same time, the average change value of the technical efficiency of research activities was more than 1 , which indicates the means and methods of scientific research creation in universities have improved over the years.

Considering the above, to improve the input-output efficiency of scientific research activities of universities, the technical efficiency of scientific research activities needs to continue improving. The degree of related technological innovation and progress in scientific research activities need to be gradually strengthened to promote the improvement of scientific research activities' performance, while promoting technical efficiency and technological advancement. Corresponding policy suggestions and identical improvement directions are provided for the relevant players to improve universities' quality and efficiency. We hope that the results of this research will be significantly helpful to the Chinese government to determine effective ways to make full use of available resources and ensure that the universities achieve balanced development for sustainable economic growth. Further, the findings of this study also offer ways for other contexts outside of China to apply practical ways to improve scientific research activities' efficiency and the optimal utilization of resources for more sustainable higher education institutions.

Despite the above said, it is essential to mention the limited ability of this research and the remaining issues that need to be addressed in future research. Broadly, the problems that remain to be examined could also contribute to the literature. This research examines the static and dynamic efficiency of scientific research of higher education institutions' universities directly under the Ministry of Education. Future research will further integrate DEA based models, the Malmquist index, and the five dimension influencing factors method to expand the research scope and compare universities' scientific research performance levels in different economic development regions in China. Similarly, to an extent, along with the environmental factors, future research can identify those factors that address the indirect link or attributes which improve scientific research performance and its sustainability in universities.

Author Contributions: Conceptualization, W.X.; methodology, W.X., R.A.; software, W.X., R.A.; validation, H.L., R.u.R. and G.F.-S.; formal analysis, W.X. and R.A.; investigation, W.X. and H.L.; resources, G.F.-S.; data curation, W.X.; writing—original draft preparation, W.X.; writing-review and editing, R.A. and R.u.R.; project administration, R.A.; funding acquisition, W.X. All authors have read and agreed to the published version of the manuscript.

Funding: There is no external funding available for this research.

Institutional Review Board Statement: Not Applicable.

Informed Consent Statement: Not Applicable. 
Data Availability Statement: Restrictions apply to the availability of these data. Data were obtained from universities' compiled science and technology statistics, the Chinese Statistical Yearbook, and the National Bureau of Statistics.

Acknowledgments: We thank the reviewers for their useful comments and suggestions.

Conflicts of Interest: The authors declare no conflict of interest.

\section{References}

1. Ministry of Education of the People's Republic of China. Compilation of Statistics on Science and Technology in Institutions of Higher Learning 2007; Higher Education Press: Beijing, China, 2008.

2. Ministry of Education of the People's Republic of China. Compilation of Statistics on Science and Technology in Institutions of Higher Learning 2018; Higher Education Press: Beijing, China, 2019.

3. Gao, Q.; He, F.; Lu, Q. Research on the efficiency of universities science and technology innovation under the background of industry-universities-research collaborative innovation-An empirical analysis based on panel data of key universities in China. Res. Dev. Manag. 2020, 32, 179-190.

4. Agasisti, T.; Barra, C.; Zotti, R. Research, knowledge transfer, and innovation: The effect of Italian universities' efficiency on local economic development 2006-2012. J. Reg. Sci. 2019, 59, 819-849. [CrossRef]

5. Scott, J.C. The Mission of the University: Medieval to Postmodern Transformations. J. High. Educ. 2006, 77, 1-39. [CrossRef]

6. Ho, M.H.; Liu, J.S.; Lu, W.-M.; Huang, C.-C. A New Perspective to Explore the Technology Transfer Efficiencies in US Universities. J. Technol. Transf. 2014, 39, 247-275. [CrossRef]

7. De La Torre, E.M.; Casani, F.; Sagarra, M. Defining typologies of universities through a DEA-MDS analysis: An institutional characterization for formative evaluation purposes. Res. Eval. 2018, 27, 388-403. [CrossRef]

8. Johnes, J. Data envelopment analysis and its application to the measurement of efficiency in higher education. Econ. Educ. Rev. 2006, 25, 273-288. [CrossRef]

9. Kempkes, G.; Pohl, C. The efficiency of German universities-Some evidence from nonparametric and parametric methods. Appl. Econ. 2010, 42, 2063-2079. [CrossRef]

10. Abramo, G.; Cicero, T.; D'Angelo, C.A. A field-standardized application of DEA to national-scale research assessment of universities. J. Inf. 2011, 5, 618-628. [CrossRef]

11. Wolszczak-Derlacz, J.; Parteka, A. Efficiency of European public higher education institutions: A two-stage multicountry approach Scientometrics 2011, 89, 887-917. [CrossRef]

12. Xiong, X.; Yang, G.L.; Guan, Z.C. Assessing R\&D efficiency using a two-stage dynamic DEA model: A case study of research institutes in the Chinese Academy of Sciences. J. Informetr. 2018, 12, 784-805.

13. Liao, J.-F.; Wang, J.; Liang, L.; Wu, Y.-D.; Huang, M.-J.; Liu, T.-Q.; Zhou, L.; Wang, X.-W. An evaluation study of research efficiency of the Guangzhou institute of respiratory diseases based on malmquist index. J. Thorac. Dis. 2016, 8, 2709-2716. [CrossRef] [PubMed]

14. Wang, X.; Hu, H. Sustainable Evaluation of Social Science Research in Higher Education Institutions Based on Data Envelopment Analysis. Sustainability 2017, 9, 644. [CrossRef]

15. Zhang, Z.; Mao, J. Performance evaluation of scientific research in universities based on DEA. Res. High. Financ. Econ. Educ. 2013, 16.

16. Qiu, Q.; Guo, M.; Zhang, Y.; Zhang, M. Evaluation of scientific research efficiency of agricultural colleges and universities based on DEA and Malmquist. Mod. Educ. Manag. 2017, 2, 50-55.

17. Gao, L.; Lu, Y. Performance evaluation and countermeasures of R\&D input-output in colleges and universities based on DEA method-A case study of 29 colleges and universities in Hebei province. Econ. Manag. 2016, 3, 45-65.

18. Wang, Y.; Chen, Y.; Cao, X.; Quansheng, F. An Empirical Study on the Efficiency and Influencing Factors of Scientific Research and Innovation in Shanghai Universities: Based on the DEA-Tobit Model. Res. Sci. Technol. Manag. 2018, 4, 100-109.

19. Jiang, T. Dynamic evaluation of scientific research performance of colleges and universities in 31 provinces and autonomous regions of China. Heilongjiang High. Educ. Res. 2012, 30, 35-38.

20. Guoli, Y.; Xie, P. Research on the efficiency of Humanities and social sciences research in 211 universities in Jiangsu Province Based on Malmquist index. Libr. Inf. Sci. Res. 2015, 4, 74-79.

21. Luo, Q. Research on the Dynamic Evolution of Scientific and Technological Innovation Efficiency in Universities and Identification of Influencing factors-based on Markov Chain Estimation and GMM Model. Math. Probl. Eng. 2021, 2021, 9831124. [CrossRef]

22. Fried, H.O.; Lovell, C.A.K.; Schmidt, S.S.; Yaisawarng, S. Accounting for Environmental Effects and Statistical Noise in Data Envelopment Analysis. J. Prod. Anal. 2002, 17, 157-174. [CrossRef]

23. Banker, R.D.; Charnes, A.; Cooper, W.W. Some Models for Estimating Technical and Scale Inefficiencies in Data Envelopment Analysis. Manag. Sci. 1984, 30, 1078-1092. [CrossRef]

24. Färe, R.; Grosskopf, S.; Lindgren, B.; Roos, P. Productivity Developments in Swedish Hospitals: A Malmquist Output Index Approach. In Data Envelopment Analysis: Theory, Methodology, and Applications; Springer: Dordrecht, The Netherlands, 1994; pp. 253-272. 
25. Caves, D.W.; Christensen, L.R.; Diewert, W.E. The Economic Theory of Index Numbers and the Measurement of Input, Output, and Productivity. Econometrica 1982, 50, 1393. [CrossRef]

26. Ray, S.C.; Desli, E. Productivity growth, technical progress, and efficiency change in industrialized countries: Comment. Am. Econ. Rev. 1997, 87, 1033-1039.

27. Tianzuo, L.; Hang, X. The Input-Output Efficiency of Scientific Researches of Universities in Different Regions and the Determination Factors Analysis: An Empirical Research Based on DEA-Tobit Model. Sci. Technol. Manag. Res. 2018, 13, 45-58.

28. Xingkai, L.; Xiaojuan, Z. An empirical study on the regional characteristics and influencing factors of scientific research efficiency in China s universities-An empirical study based on three-stage DEA method. J. Natl. Acad. Educ. Adm. 2015, 5, 77-83.

29. Li, X. Research on the Performance of Discipline Inspection and Supervision Institutions in Universities; China University of Science and Technology: Taipei, Taiwan, 2014.

30. Dongshan, W. Research on Influencing Factors of Scientific Research Performance of University Teachers; Beijing Forestry University: Beijing, China, 2012.

31. Dongyun, Y.; Xiangrong, J. Comparative study on innovation efficiency of innovation subjects. Sci. Res. Manag. $2014,3,51-57$.

32. Wu, J.; Zhang, G.; Zhu, Q.; Zhou, Z. An efficiency analysis of higher education institutions in China from a regional perspective considering the external environmental impact. Scientometrics 2020, 122, 57-70. [CrossRef] 